\title{
La corrupción judicial
}

\section{María González de Asís *}

\section{Introducción}

La corrupción judicial es una forma especialmente grave de corrupción pública. La corrupción en el sistema judicial tiene lugar cada vez que un miembro de la magistratura busca 0 recibe un beneficio o promesa de un beneficio de cualquier clase a través de un abuso de poder debido al cargo. Tal abuso incluye el soborno, el fraude, la utilización de recursos públicos para beneficio privado y la pérdida deliberada de archivos judiciales. La corrupción también se da cuando los procedimientos no se resuelven en base a la ley, sino que se deciden por presiones, influencia indebida, amenazas o la interferencia política.

Desde finales de los años ochenta, los gobiernos de, por lo menos, veinticinco países han lanzado programas diseñados para aumentar el profesionalismo, la eficacia y la credibilidad de sus sistemas judiciales. Estos esfuerzos reflejan el compromiso de los gobiernos para llevar a cabo planes de reforma y el apoyo de patrocinadores para enfrentarse a la corrupción en un contexto más amplio de reforma judicial. Distintas agencias patrocinadoras bilaterales y multilaterales -incluyendo la United States Agency for International Development (USAID), la Agencia bilateral alemana GTZ, el Banco Interamericano de Desarrollo (BID) y el Banco Mundial_ - incluyen actualmente en sus proyectos medidas específicas para luchar contra la corrupción judicial.

Reconociendo la complejidad para diseñar y llevar a cabo reformas judiciales, el presente trabajo intenta presentar algunos resultados importantes sobre los principales problemas que se encuentran en los sistemas judiciales y algunas sugerencias hechas por expertos y patrocinadores internacionales que trabajan en este área. Aunque este trabajo se centra en la corrupción en el sistema judicial, se reconoce que la acción en esta área tiene que estar relacionada con las circunstancias generales de tipo político, social y económico de las reformas institucionales que se llevan a cabo en un país.

\section{Reformas judiciales}

El Banco Mundial es cada vez más consciente de la complejidad y el efecto dañino de la corrupción dentro del sistema judicial, y está incluyendo medidas específicas para combatirla como parte de una amplia agenda de reformas institucionales. Los tipos de reformas que promueve el Banco se tratan a continuación.

\section{La independencia del sistema judicial}

La politización del sistema judicial, particularmente de jueces y fiscales, es un grave problema para la corrupción. La politización puede surgir por el uso de procedimientos arbitrarios y faltos de transparencia para seleccionar y despedir a los jueces, unido a la circunstancia del corto plazo del período para el que son nombrados (de cuatro a seis años para jueces y fiscales). Los criterios políticos basados en cuotas regionales y de partido se usan, algunas veces, para el nombramiento y el despido de los jueces. En muchos países, los licenciados mal pagados de las facultades de Derecho tienen la costumbre de meterse en la política para conseguir juzgados, cuando sus perfiles profesionales y psicológicos están lejos del ideal. Los criterios de nombramiento en estos casos se basan, principalmente, en el de clientelismo político y el de influencia. Cuando esto se une a la falta de un sistema efectivo de carrera judicial eficaz y a una excesiva discrecionalidad en el reparto del presupuesto 
y asignaciones de personal, estos criterios llevan a una desintegración total del «cortafuego» entre un sistema de tribunal independiente y el sistema político.

Normalmente, los sistemas judiciales también carecen de indicadores de actuación aplicables. La ausencia de mecanismos efectivos para medir su actuación crea estímulos para tomar decisiones de forma arbitraria basadas en relaciones personales y políticas y hace que los jueces del nivel más bajo sean demasiado dependientes de los jueces del nivel superior que, normalmente, están más motivados políticamente. Los controles externos son también una parte importante de la supervisión del sistema judicial para asegurar que los mecanismos de control interno funcionen.

La revisión de los procedimientos de selección, nombramiento, remuneración y despido de los jueces y fiscales de forma que queden aislados de la influencia política es, por tanto, una condición sine qua non para asegurar la imparcialidad e independencia del sistema judicial. Tales procedimientos incluyen descripciones claras del trabajo que deben realizar y de las cualificaciones necesarias, comprobaciones sistemáticas del pasado de los antecedentes de los candidatos a la rama judicial y del personal de apoyo y una supervisión habitual para evitar la incompetencia y la corrupción, establecer la creación de incentivos profesionales claros basados en recompensas y penalizaciones e introducir indicadores del funcionamiento para determinar las promociones individuales, las recompensas y los aumentos de sueldo.

Los esfuerzos por fortalecer la independencia judicial pueden, sin embargo, encontrar serias dificultades. En muchos países, un ejecutivo poderoso se resiste a cualquier interferencia en su autoridad, mientras en otros la corrupción está ligada a la economía, la política y el crimen organizado.

\section{Derecho procesal}

Las infracciones de Derecho procesal representan una de las formas más extendidas de corrupción en el sistema judicial. A los empleados judiciales se les paga por retrasar o acelerar un caso de forma artificial. En otras ocasiones, se les recompensa simplemente por realizar los servicios normales como entregar una notificación o tomar una declaración durante la fase de acopio de pruebas.

Los retrasos se concentran, principalmente, en las notificaciones y citaciones y durante el «dictado de autos y sentencias». Los retrasos procesales se usan como una herramienta estratégica por abogados y tribunales para conseguir pagos de los litigantes. Esto ocurre cuando falta un control efectivo del caso y mecanismos de seguimiento. En este contexto, no es posible generar incentivos para una mejor actuación y una con- ducta honrada cuando no pueden llevarse, o ni siquiera definirse, normas de actuación para los jueces y personal auxiliar. La definición de estas normas a través de técnicas de control de calidad es, por consiguiente, clave para identificar con precisión las irregularidades, disuadir el soborno y proporcionar incentivos que mejoren la eficiencia.

\section{Financiación y retribución}

El sistema judicial exige una financiación adecuada para funcionar eficazmente. Los niveles de financiación deben ser una prioridad en el presupuesto y deben estar determinados de acuerdo con la magistratura. La financiación y la retribución son de gran importancia para controlar la corrupción en la magistratura, porque si los sueldos no permiten un nivel de vida adecuado al puesto, la tentación de recibir dinero ilegalmente es grande. Un sueldo más alto atrae y retiene a una clase de empleados judiciales de más calidad, pero sólo un sueldo adecuado es insuficiente para alejar el peligro de que los que toman decisiones caigan en tentaciones.

Se necesitan otras medidas de prevención. Una que parece particularmente eficaz es la publicidad del activo y pasivo en el momento del nombramiento y, anualmente, a partir de este momento al mismo tiempo que se desplaza la carga de la prueba por adquisiciones de bienes no explicables por parte del funcionario en cuestión. Esto expone a los funcionarios corruptos a la obligación de justificar sus bienes y nivel de vida. En algunos países, la magistratura confisca los bienes y el dinero cuyo origen el funcionario público no puede justificar.

Para establecer una escala de salarios para todos los empleados de la rama judicial que sea satisfactoria, los sueldos de los jueces del Tribunal Supremo deberían estar vinculados a los de los legisladores, y los demás sueldos de la rama judicial deben elevarse consecuentemente.

\section{La tecnología}

Las lagunas en los sistemas de información y las inconsecuencias legales son una fuente importante de excesiva discrecionalidad. La falta de suficiente cuidado de los registros, en el seguimiento de los casos, gestión de archivos, el rotulado y los detalles administrativos también contribuyen a la corrupción. Los miembros de la magistratura que decidan resolver los casos de manera corrupta pueden hacerlo con una alta probabilidad de que sus acciones no se revisarán ni se cuestionarán. Un sistema moderno informatizado puede simplificar los procedimientos administrativos y mejorar la transparencia en el seguimiento de los casos. Los sistemas de datos permiten revisiones del desempeño del trabajo o acciones en casos específicos 
y también captar una información completa sobre la duración de los casos y forma de preparación de los mismos en cada etapa de un caso.

\section{La profesionalización de la magistratura}

La falta de meritocracia y la politización en la magistratura socava el profesionalismo y alimenta la corrupción: las decisiones sobre la promoción, la selección y el nombramiento de los jueces son normalmente arbitrarias y no se basan en el desempeño de la tarea o la experiencia profesional. A veces los jueces son designados por los diversos partidos políticos o incluso por las facciones dentro de los partidos, y esos partidos o facciones responsables de su designación esperarán una recompensa por parte de los jueces en la realización de sus trabajos, tales como la aceptación de sugerencias para las decisiones y la aceleración en la resolución de los casos.

Para conservar el principio de independencia, es indispensable aislar la institución del clientelismo político y del patrocinio. La promulgación de una nueva y viable ley de la carrera judicial disminuiría la interferencia potencial de las políticas y encauzaría estos problemas por medio de la creación de incentivos profesionales basados en recompensas y sanciones (promociones previsibles y rotaciones que impliquen mejoras).

Mejorar el profesionalismo es otra medida importante para prevenir la corrupción en el sistema judicial. La formación continua para jueces y la formación para los otros funcionarios judiciales no sólo mejoran sus capacidades para desempeñar sus tareas, sino también mejoran su sentido de la responsabilidad para el trabajo. En general, proporcionar un espacio adecuado y recursos, incluyendo medios de transporte, servicios de información y protección, pueden mejorar la moral y la imagen de la profesión. Además, es crucial establecer normas de conducta para los empleados de la rama judicial y un sistema de disciplina formal que haga cumplir estas normas de forma regular, igualitaria y justa.

Estas medidas de reforma también irían dirigidas a la conducta oportunista que prevalece entre el personal judicial. La baja formación y la poca motivación del personal judicial son debidas, principalmente, a prácticas y estructuras organizativas imprevisibles. El aislamiento de la presión política es necesario para asegurar personal profesionalizado y un sistema judicial creíbles.

\section{Técnicas especiales de investigación}

El sistema judicial debe realizar las investigaciones en colaboración con otros organismos comprometidos a fin de tener un intercambio de información apropiado tanto dentro del país como con otros países. Algunas medidas facilitan las investigaciones, como el acceso a los registros bancarios, informes fiscales, declaraciones financieras, las comunicaciones interceptadas y pruebas obtenidas. La legislación debe proteger el derecho a la privacidad, pero, al mismo tiempo, permitir que las investigaciones basadas en sospechas razonables puedan llevarse a cabo. En algunos países también la independencia creciente de la magistratura está llevando a una mayor persecución de los casos de corrupción, como en Italia y la India. Además, una ayuda importante en la persecución de los casos de corrupción surge en países donde las carreras de fiscales y jueces no están separadas. A través de este sistema, los fiscales pueden participar en la cultura judicial y los jueces pueden valorar los aspectos técnicos de la investigación.

\section{Enfoques para la reforma}

El Banco Mundial es cada vez más consciente de la complejidad del proceso de reforma. El trabajo realizado hasta la fecha ha puesto de manifiesto que las herramientas de diagnóstico, la implicación de la sociedad civil y los medios de comunicación independientes y responsables son elementos cruciales para el éxito en las iniciativas anticorrupción.

\section{Herramientas de diagnóstico}

Los estudios de diagnóstico son una herramienta poderosa para desmontar la corrupción e identificar áreas problemáticas dentro del sistema judicial. Ello puede centrar el diálogo, ayudar a definir medidas y resultados esperados y mejorar la comprensión global del proceso de la reforma. La información generada por los diagnósticos permite a los reformadores evitar las limitaciones del pasado debido a la falta de una agenda precisa, de objetivos y estrategias. Sin embargo, quienes realizan los estudios tienen que ser independientes y utilizar una metodología rigurosa, de otra manera, los resultados pueden resultar engañosos y ser mal utilizados.

Para que el trabajo de diagnóstico resulte tan eficaz como sea posible, éste debe incluir la evaluación de necesidades, establecer relaciones con otros países u organismos que trabajan en el mismo área e integrar las nuevas medidas en las estrategias de reforma existentes en el país. Además, el análisis del sistema judicial debe basarse en estudios internacionales que podrían sugerir mejores prácticas o llamar la atención sobre medidas adaptadas a un contexto cultural, político, social y económico dado.

El reto para los reformadores, los funcionarios públicos, la sociedad civil y los patrocinadores es capitalizar las ideas y el 
impulso generado por los diagnósticos, pasar del diagnóstico a la acción y hacer progresos significativos basados en datos fiables.

\section{Sociedad civil}

Una vez que el trabajo de diagnóstico ha identificado las áreas prioritarias en las cuales centrarse, la sociedad civil debe involucrarse en el diseño y puesta en marcha de las reformas judiciales. La sociedad civil y las ONGs específicas pueden promover el conocimiento público del sistema legal revisado, proporcionando una comprensión general de las reglas formales e informales. Esto permite a los ciudadanos, como beneficiarios directos de los servicios de la justicia, tener acceso a ellos y proponer modificaciones para reducir la distancia entre las leyes formales y las informales. Algunas ONGs también pueden ayudar al sistema judicial en el diseño de sistemas de nombramientos judiciales basados en el mérito y sistemas de evaluación $y$ en ofrecer los servicios de ADR.

Además, la sociedad civil puede jugar un valioso papel en el control del funcionamiento judicial. Las oficinas del defensor del pueblo, los organismos anticorrupción, los think tanks, las universidades y las ONGs pueden servir como guardianes y pueden presionar a sistemas en los que los funcionarios parecen disfrutar de inmunidad legal. También pueden revisar los mecanismos de cumplimiento, reunir las estadísticas y las evaluaciones del funcionamiento judicial y hacer que esta información sea accesible al público.

En el nivel internacional las ONGs constituyen un elemento inestimable de presión para ratificar y llevar a cabo convenios, leyes transnacionales e internacionales. Animar a las organizaciones internacionales, nacionales y locales, incluyendo las asociaciones de colegios de abogados, para ayudar a la prevención y la eliminación de la corrupción del sistema judicial es importante para crear independencia judicial. Los colegios de abogados deben adoptar sanciones profesionales fuertes y eficaces contra cualquier conducta de esta clase por los miembros de la profesión legal.

\section{Unos medios de comunicación independientes y responsables}

Los medios de comunicación juegan un papel crucial en el desarrollo de la conciencia pública y para animar la participación pública en el proceso de exponer, prevenir y eliminar la corrupción en el sistema judicial. Los medios de comunicación pueden favorecer una cultura de intolerancia hacia la corrupción en el sistema judicial. El sistema judicial debe, por tanto, formular propuestas para mantener al público, incluyendo los medios de comunicación, informados e instruidos en cuanto al funcionamiento del sistema judicial, por ejemplo, mediante la grabación de las decisiones judiciales de los tribunales y haciendo que los expedientes judiciales estén abiertos al público. La presión pública podría, indudablemente, ayudar a retirar la inmunidad y procesar a un funcionario corrupto, si se facilitan pruebas suficientes a través de los medios de comunicación.

\section{Conclusión}

El Banco Mundial está dando un paso importante al reconocer que necesita hacer mucho más trabajo en el terreno de la lucha contra la corrupción dentro de la judicatura, y que el éxito requeriría una apertura a la sociedad civil y a los medios de comunicación. Las medidas subrayadas en este trabajo señalan que un sistema judicial independiente es crucial para cualquier estrategia anticorrupción al igual que establecer normas éticas, cauces disciplinarios formalizados y funciones internas y externas de supervisión para la magistratura. Sin embargo, todas estas medidas son sólo un primer paso en el intento de frenar la corrupción de una manera amplia como parte de la estrategia global anticorrupción de un gobierno. El desafío para el Banco Mundial es llevar el trabajo adelante en la práctica, y hacerlo con un énfasis que comprometa a la sociedad civil, siendo flexible, y valorando los obstáculos políticos, sociales y económicos en relación con la corrupción.

* Instituto del Banco Mundial. 